\title{
The malnutrition bazaar: the case of RUTF
}

\author{
Radha Holla Bhar \\ holla.radha@gmail.com
}

\section{Abstract}

Severe acute malnutrition (SAM) in children is life-threatening. Its causes range from lack of access to balanced food, to incorrect feeding practices, lack of access to an efficient health system, to clean potable water and sanitation. However, the present approach to managing SAM is fortified packaged food - a paste made with peanuts or other protein rich food such as chickpeas, milk and sugar, to which micronutrients are added. Currently, a version of the paste with less energy levels is also being recommended for treating even moderate forms of malnutrition, as well as for prevention of malnutrition (World Health Organization (WHO), 2012; WHO/UNICEF/WFP, 2014; WFP/UNICEF/USAID, undated).

The large number of malnourished children around the globe furnish the food and pharmaceutical industries with an immense potential market for these fortified food packages. That the market for ready-to-use therapeutic foods (RUTFs) is rapidly expanding is primarily due to its endorsement by the World Health Organisation (WHO, the World Food Programme, the United Nations System Standing Committee on Nutrition ${ }^{1}$ (UNSCN) and UNICEF for treating SAM (World Health Organization, the World Food Programme, the United Nations System Standing Committee on Nutrition and the United Nations Children's Fund. (2007).). Non state actors like Action Against Hunger (Action Contre La Faim) and Médecins Sans Frontières have also been working to introduce RUTF treatment in countries such as Ethiopia, Nigeria, Libya, Chad, Central African Republic, Malawi, Yemen, India and Pakistan. In addition, several of the new manufacturers use unethical marketing practices to increase their share of sales.

The long-term sustainable solution to reducing undernutrition has to be based on policies that manage conflict, inequity, gender imbalance, food sovereignty and security, infant and young child feeding, basic health services and provision of safe drinking water and sanitation.

\section{INTRODUCTION}

Malnutrition takes several forms - undernutrition which comprises moderate and severe wasting, stunting, micronutrient deficiencies, and obesity. Undernutrition in particular, accounts for around $45 \%$ of deaths among children under-fives years of age; these deaths occur mostly in low- and middle-income countries (WHO, 2020). The latest data released by

\footnotetext{
${ }^{1}$ In 2020, the UN Network for SUN (UNN) merged with the United Nations System Standing Committee on Nutrition (UNSCN) to form a new entity, called UN Nutrition. As of 1 January 2021, the UN Nutrition Secretariat, hosted by FAO headquarters, became operational.
} 
UNICEF/WHO/WB Joint Child Malnutrition Estimates (JME) group on $31^{\text {st }}$ March 2020 highlight the fact that South Asia has the highest percentage of children who are both severely wasted $^{2}$ as well as severely and moderately wasted ${ }^{3}$ (WHO, 2020).

Severe wasting, or severe acute malnutrition (SAM) is life-threatening. Its causes include poor access to appropriate, timely and affordable health care; inadequate caring and feeding practices (e.g. exclusive breastfeeding or low quantity and quality of complementary food); poor food security - not only in humanitarian situations, but also an ongoing lack of food quantity and diversity, characterized in many resource-poor settings by a monotonous diet with low nutrient density, together with inadequate knowledge of patterns of food storage, preparation and consumption; and lack of a sanitary environment, including access to safe water, sanitation and hygiene services (WHO, 2014). This review is about a short-term approach being pushed by donor agencies who often are ignoring or downplaying these long-term solutions because their bias is all too often oriented toward the marketplace as the solution to the problems of lowincome countries.

\section{PACKAGED FOODS AND THE MANAGEMENT OF MALNUTRITION}

Children who are wasted are more at risk of dying. It therefore makes a kind of sense that reducing deaths by undernutrition, particularly wasting, will immediately reduce the number of under-5 deaths. A peanut-milk-sugar-micronutrient paste called Plumpy'nut ${ }^{\mathrm{TM}}$, developed by a French doctor, Andre Briend in the late 1990s while working in Africa, appeared to be an effective treatment for wasting. African children on a Plumpy'nut regimen gained weight rapidly, blazing a trail of glory for the magic bullet. In public health, where years of toil and commitment leads but to incremental improvements, Plumpy'nut offered quick, visible efficacy. It soon caught global attention and several businesses today are vying with each other to capture the market for their versions of Plumpy'nut.

Plumpy'nut is a prime example of how to make a fortune by catering to the "bottom of the pyramid", as exhorted by Prahalad and Hart in 2002: creating and dominating emerging opportunities by recognizing the poorest of the poor as a new and immense market for goods tailored to meet their needs (Prahalad \& Hart, 2002). This new strategy gave business, with their capacity to make products, the opportunity to enter into development dialogues as a vital stakeholder. In consonance with growing neoliberal efforts to increase the role of the private sector and decrease that of the public sector, the Global Alliance for Improved Nutrition (GAIN) and the Scaling Up Nutrition (SUN) initiative were set up in 2002 and 2010 respectively to mobilise public-private partnerships to treat and reduce malnutrition across countries.

\footnotetext{
${ }^{2}$ Wasting (severe): percentage/number of children aged 0-59 months who are below minus three standard deviations from median weight-for-height of the WHO Child Growth Standards.

${ }^{3}$ Wasting (moderate and severe): percentage/number of children aged 0-59 months who are below minus two standard deviations from median weight-for-height of the WHO Child Growth Standards.
} 
In the wake of the invention of Plumpy'nut ${ }^{\mathrm{TM}}$, researchers and scientific journals highlighted the role of fortified foods for treating malnutrition. For example, the Lancet Nutrition Interventions Review Group, and the Maternal and Child Nutrition Study Group estimated that the cost involved to achieve $90 \%$ coverage of the population in need in the 34 focus countries with the selected set of ten nutrition interventions would be $\$ 9.6$ billion per annum, of which micronutrient interventions accounted for the largest share, 39\%--\$3.7 billion (Bhutta et al., 2013). The interventions include not just fortification of grains but also supplementation and bioengineering to produce varieties of commonly consumed plant species with high levels of the required micronutrient such as Golden Rice.

\section{EVIDENCE GENERATION, DECISION-MAKING AND CONFLICT OF}

\section{INTEREST}

RUTF has been promoted worldwide citing research conducted mainly in Africa; this research is flawed in that it rarely compared RUTF with an augmented regular balanced meal using diverse, concentrated foods. Referring to the recommendations given by the Lancet Series on maternal and child nutrition, 2013, Greiner states, "admitting the lack of hard research evidence, the Lancet article cites 'substantial programmatic evidence' as a basis for its recommendations. This, it turns out, is a single article by Steve Collins, who happens to run an organization that makes money selling RUTF" (Greiner T, 2014). An IBFAN policy brief lists several other trials which cast doubts on the efficacy of RUTF as compared to treating SAM with enriched food (IBFAN, 2017). There are also several studies debunking RUTF as a miracle food for reducing SAM (Nutrition Advocacy in Public Interest (NAPi), 2017), as well as studies on the use of family foods and interventions that include improving care practices (Gope et al., 2019; Prasad, 2015; PHRN \& APPI, 2021) as well as critiques of studies promoting the use of RUTF (Prasad, 2017).

Visser et al. (2018) question the effectiveness of RUTF, especially as the only intervention to deal with SAM. Summarizing eight systematic reviews to describe and explore the effects of supplementary feeding given to children and adults, including pregnant and lactating women, in food insecure, vulnerable and malnourished populations. They conclude, "We have observed modest benefits (mostly in terms of anthropometric parameters) for some outcomes across studies, with a variety of supplementary feeding interventions. Mortality evidence is limited, with some evidence in newborns that supplementing the mother reduces the risk of stillbirth. The certainty of the evidence overall was moderate to very low (often including one or two small trials)." Reviews mostly reported on short-term outcomes, with very few trials investigating crucial long-term outcomes. Some important outcomes were reported rarely (e.g., quality of life) or not at all (e.g., cost aspects). The findings reinforce the multi-dimensional nature of food insecurity and malnutrition, with supplementary feeding programmes only one of the approaches needed to address these complex issues. An integrated approach seems crucial, with investigations on how best to combine supplementary feeding programmes with other interventions to achieve the desired nutrition and health outcomes. Ultimately it remains unrealistic to expect that a single intervention will be the ultimate solution (Visser et al., 2018). 
Studies such as those of Visser and PHRS appear to be ignored by international organizations and national policy makers, as well as many non-state actors (NSAs). The Emergency Nutrition Network (ENN) publication Field Exchange of October 2020 focused on a study with a more convenient conclusion, saying, "Regional research on this front continues by ICCDR in Bangladesh while an article in this issue from India by Achakzai et al. describes experiences of testing an alternative formulation for wasting treatment based on a locally adapted product. In the India experience, both milk protein content and observed weight gain do not meet current global standards/benchmarks." (Field Exchange, 2020).

As Visser points out, treating SAM with RUTF addresses only one of the several causes of SAM - the immediate one, lack of access to food and specific nutrients. Nevertheless, RUTF has been endorsed by WHO, the World Food Programme (WFP), UNICEF, United Nations High Commissioner for Refugees (UNCHR), United States Agency for International Development (USAID), as well as NSAs such as GAIN, Bill \& Melinda Gates Foundation, Hellen Keller Institute, and humanitarian agencies such as Action Against Hunger (Action Contre La Faim or ACF) and Médecins Sans Frontières (MSF) (WHO, 2019), who use it in specific projects and programs in India and several African countries, often under waivers from national regulators (WFP \& MSF, 2018).

The global decision-making processes promoting the use of RUTF are replete with coincidences, which could give the appearance at least of conflicts of interest (Arie, 2010), especially when the NGO that prescribes this regime of treatment manufactures the product. The 2015 annual report of Valid Nutrition notes, 'This is the first step in a progressive program we have designed to start the process of unlocking this potentially massive market'. It recently expanded RUTF operations to India in partnership with India's largest private food brand and dairy, Amul, which sells vast quantities of milk powder and sugar sweetened beverages (Valid Nutrition, 2016).

\section{THE GROWING MARKET FOR RUTF}

Subsequent to UN agencies' endorsement of the RUTF regime for treating SAM both in health facilities and in the community, there has been a growing demand for RUTF. Transparency Market Research estimates that the demand in the global market for RUTF and ready-to-use supplementary food (RUSF) will increase at a compound annual growth rate of $8.6 \%$ during the period 2017 to 2025 , up to a worth US $\$ 829.3$ from US\$429.9 million in 2017. This is a reflection of a number of factors, such as increased government and NGO concerns regarding malnutrition treatment, growing malnutrition as a result of escalating population across the globe, rising demand for drinkable RUTF products, and an anticipated increase in the number of emergencies and disasters in various parts of the world (Transparency Market Research, 2017).

The growth of the market for RUTF is driven by international organisations such as UNICEF, SUN and GAIN as well as international NGOs like MSF, ACF and Helen Keller Foundation. The pathways for this growth include humanitarian aid and community management of malnutrition, among others. 


\section{Ready-to-use foods as humanitarian aid}

Human distress, especially in times of conflict and natural disasters like floods, earthquakes, fires, drought and volcanic eruptions, can lead to severe malnutrition, which can be fatal especially in children; in such instances, where there is inadequate access to food, RUTF can be a handy solution to treat or prevent malnutrition. For instance, such RUTF packets can be airdropped, or transported easily in large quantities to meet the hunger needs of the affected population, till other measures can be put in place. However, malnutrition persists in many countries even in times of peace, when there is no natural calamity. The WHO has set a threshold to evaluate whether the situation of malnutrition constitutes an emergency or not. According to WHO, a crisis or emergency exists when the presence of both moderate acute malnutrition (MAM) and SAM in children, a condition known as global acute malnutrition or GAM, is greater than $10 \%$ in the child population (WHO, 2000). This applies both in the short term and in the long term.

While SAM continues to be treated using RUTF in both facilities and community settings in an emergency, in several countries MAM is being treated with fortified flours and RUSF like Plumpy'Doz ${ }^{\mathrm{TM}}$ through blanket feeding programmes (USAID, 2017). WFP is already distributing Plumpy'doz and supplementary Plumpy ${ }^{\mathrm{TM}}$. However, studies have shown contradictory results. A study in Chad by Lieven et al. concluded that there was no clear evidence that adding RUSF to a household food ration effectively prevents wasting, calling for alternative ways to be investigated to prevent acute malnutrition in Chad and other vulnerable regions of the world (Lieven et al., 2012). Steenkamp et al. (2015) question the use of RUSF to reduce MAM in non-emergency settings. "As children in this study did not benefit from targeted supplementation beyond six weeks, the question may well be asked whether it can be justified in providing expensive supplements to children with moderate malnutrition resulting from food insecurity in households. Channelling of those funds to support community-based interventions for the improvement of household food production may be of more value in this particular group, rather than attempting to achieve catch-up growth in children residing in hungry households." (Steenkamp et al., 2015).

\section{Community-Based Management of Acute Malnutrition (CMAM)}

An important driver of the growing market for malnutrition is the increasing emphasis on community-based management of acute malnutrition (CMAM), described by WHO as a "community approach" that emphasizes "timely detection" of SAM, and ensures that children with uncomplicated SAM are provided with treatment that includes provision of RUTF (WHO et al., 2007). According to UNICEF, CMAM is a community outreach of a medical facility (UNICEF, 2013), which reduces the role of the community to mere identification and supervision in the community of the same treatment often given nowadays in a medical facility. For instance, the program does not include measures to prevent further deterioration when growth faltering is first noticed. Nor does the program include treatment of SAM with locally available resources, which have been shown to be effective, and which in addition, support community agriculture and lead to changes in feeding practices so that relapses are prevented (Prasad, 2017). 
The Emergency Nutrition Network (ENN) special issue on child wasting in South Asia notes that "failure to scale up treatment in the region may partly reflect a reticence to take on treatment when there is no clear vision or plan on how it can be sustained". However, it reports that in India, Pakistan and Nepal, government leadership has enabled working towards embedding CMAM into existing systems and services, and, in India, will work towards reorganizing the health system to facilitate this integration (Field Exchange, 2020).

\section{THE PLAYERS}

UNICEF

UNICEF is the world's largest procurer of RUTF, mainly as emergency response. The agency's procurement reached 35,000MT in 2015 and 33,000MT in 2016, representing a four-fold increase since 2009. Currently, it procures an estimated 75-80 per cent of the global demand for RUTF, averaging 49,000 metric tons (MT) per year over the last four years, covering approximately $25 \%$ of SAM children across the world. (UNICEF Supply Division, 2021). The agency estimates that with scaling up of programs to cover the estimated 8-9 million children who are severely malnourished, the market for RUTF would expand. Other procurers include USAID, MSF, and ACF, which together account for 5\% of the global estimated SAM caseload (UNICEF, 2017). As the production capacity today exceeds demand, the use of RUTF is also being advocated for treating MAM as well as for preventing malnutrition (World Health Organization (WHO), 2012; WHO/UNICEF/WFP, 2014; WFP/UNICEF/USAID, undated). This would mean that a large proportion of children in low-income settings would be a potential market for RUTF.

From 2000-2007, the French company Nutriset, was the sole international supplier of RUTF. Since then, given UNICEF's policy of encouraging national production that encouraged independent, quality suppliers, particularly in programme countries, it now procures RUTF biscuits from 22 manufacturers located in 16 countries including India, Pakistan, USA, Norway, and several African countries (UNICEF Supply Division, 2021).

In India, there has been a lot of pressure exerted by UNICEF and international NGOs to integrate RUTF in the national guidelines for treating SAM. However, due to advocacy by leading domestic paediatricians, nutritionists and public health experts, both the Ministry of Health and the Ministry of Women and Child Development sent letters to their state departments to treat malnutrition with augmented home foods, and not RUTF. This was ignored by some states, who have been partnering with ACF and other NGOs to distribute RUTF. In the meantime, NITI Aayog, India's premier policy making body, bent on liberalization, gave states the liberty to choose to give RUTF, paving the way for large-scale entry of RUTF into the country.

UNICEF and international NGOs use several strategies to pressurize countries to integrate RUTF and other packaged products into their health and nutrition systems. The primary strategy is advocacy. Field Exchange reports, "In Pakistan, partners capitalized on the Government's signing of the Astana Declaration on Universal Health Coverage and successfully advocated to include community-based management of acute malnutrition (CMAM) in the public health system" (Field Exchange,2020). 
UNICEF and donor agencies frequently work closely with health ministries and departments, especially in middle- and low-income countries, and often influence their health and nutrition policies. In addition, they hold conferences and seminars where "experts" from across the world meet and highlight the role of packaged food for treating and preventing malnutrition. Research that devalues local foods and diets is used to strengthen their arguments. UNICEF hosts a Nutrition Supply Forum every couple of years, bringing together manufacturers, partner organizations, UNICEF staff, donors and academia, to exchange ideas, best practices, and updates on supplies and procurement of products for nutrition programmes (UNICEF Supply Division, 2021).

Another strategy being used by UNICEF and being supported by ACF and other international organizations is advocacy to include RUTF in WHO's Essential Medicines List (UNICEF, 2017), turning malnutrition into a medical problem rather than one that needs to be addressed by several measures including structural reform to reduce inequity in populations and ensuring access to food as a human right. So far, RUTF has been included in the Essential Medicines List of Niger, Burkina Faso, Nigeria, Guinea, Haiti, Madagascar and Sudan (WHO, 2019). UNICEF continues to advocate that countries scale up their programs to increase the demand for RUTF, and to fully integrate these products into their health and nutrition systems supply chain (UNICEF, 2017).

A third strategy has been to have Codex discuss the proposed guidelines for use of RUTF (UNICEF, 2019). Codex sets standards for food among other things. It facilitates global trade. Once Codex accepts to discuss the proposed guidelines for any food, the food is officially accepted for purposes of trade. Though Codex may take up to eight years to come to a decision, it can be used by manufacturers and distributors to put pressure on governments to accept imports of products that may not be needed or wanted. For instance, the Codex Standard covering Formulas for Special Medical Purposes (CODEX STAN 72 - 1981) has led to an increase in inappropriate marketing of these products.

\section{SUN (Scaling Up Nutrition)}

Besides UNICEF and WHO, international bodies like the Global Alliance for Improved Nutrition (GAIN) and the Scaling Up Nutrition (SUN) also exert pressure on countries to mainstream the use of RUTF for treating undernutrition. Their primary strategy is to convince countries to collaborate with industry to make products towards this end.

The SUN collaborative process, which began in 2009, is based on the Scale Up Nutrition Framework published in the March 10, 2010 in the Food and Nutrition Bulletin. SUN calls itself a "movement" that is "led by governments, supported by organisations and individuals" (SUN Movement, 2015) that pushes for collective action to improve nutrition of children. The primary strategy is to bring together country decision makers, donors, and the private sector, with some representation from civil society. This so-called movement includes the following:

- Country network--over 60 countries and three States in India are members as of now. A SUN Focal Point is appointed in each country and region to facilitate the process of 
countries aligning themselves to the SUN Framework for Action and in raising funds for implementing it.

- Donor network--which includes WHO, UNICEF, WFP the UN Food and Agricultural Organisation (FAO), the Bill and Melinda Gates Foundation, the Children's Investment Fund Foundation (CIFF), and others.

- Civil society network-which includes national alliances and international NGOs such as Save the Children, Concern Worldwide, World Vision International, the Hunger Project, Terre des Hommes, Helen Keller Foundation, Wateraid, Wash, and ACTION, among others

- Business network--members include Hersheys, Pepsico, Unilever, Ajinomoto, BASF, Britannia, Cargill, Nutriset, DSM, Tetra Laval, Indofood, Mars, Syngenta, KPMG, Valid Nutrition, Amway, Edesia, Nutrifood, Rabo Bank, and Barclays, among others. The SUN business network had over 300 members, including both multinational and national companies, by 2016. It claims to provide "a neutral platform to broker partnerships and collaborations between business and all actors on nutrition at the national, regional and global level in support of SUN Countries". It is co-convened by GAIN and WFP.

\section{Other external funders}

Aid agencies of countries such as USAID, the UK Department for International Development (DfID) and Irish Aid have purchased significant quantities of RUTF. In aiming to shape the market, DfID played a catalytic role in bringing together Amul and Valid International in India, where the former has started manufacture of RUTF with technological inputs from the latter. The agency notes that while Amul's priority is producing for the local market, that "once the domestic market accepts RUTF in the treatment of SAM, global market may not be a priority for Amul" (DfID, 2018).

UNICEF partnered with USAID in 2011 to make in-kind donation of 527MT of RUTF to four countries. The partnership expanded the donation to 21 countries in 2015 and 2016, to reach 10,000MT (UNICEF 2017). Donations by USAID have been supporting therapeutic feeding in 25 countries in Africa, in addition to Afghanistan, Bangladesh, Haiti, Myanmar, Pakistan, and Yemen (UNICEF Supply Division, 2021).

In Malawi, Irish Aid supports the production of RUTF by VALID Nutrition and AgDevCo, a local company. While production is estimated to start in mid-2021, in 2020 the aid agency supported a major research project for a new line of ready-to-use complementary food (RUCF) designed to prevent chronic malnutrition. This included a willingness to pay study as well as a landscaping study to understand infant and young child feeding (IYCF) practices in Malawi, together with pre-use, qualitative research to develop an appropriate marketing mix and brand. According to VALID Nutrition, "these are first steps in a progressive programme designed to start the process of unlocking this potentially massive market, and bringing autonomy and food choices to individuals affected by malnutrition" (VALID Nutrition, 2020).

Insta Products, which manufactures RUTF in Nairobi, and is one of the top suppliers to UNICEF globally, has been financially supported by the International Finance Corporation (IFC). While 
IFC has given half the loan, the other half has been contributed through the private sector window of the Global Agriculture and Food Security Program (GAFSP), which IFC manages. In addition, the Danish government fund IFU is supporting the project with a $\$ 4$ million loan. The investment aims to help the company expand its RUTF capacity and more than double its sales on the back of an increased supply (IFC, 2017).

\section{Private sector players}

The growing market for RUTF and RUSF, and thus the increased opportunity for making profits has led to other companies entering the packaged fortified food business (Transparency Market Research, 2017; Prorodeo, 2021). Several members of the SUN Business Network and members of the GAIN Alliance are experimenting with various ingredients like chickpeas and other pulses to make a commercially viable RUTF that can compete with Plumpy Nut (Thekleberhon M, 2012; Prorodeo, 2021). A number of regional players in Europe are increasing their production capacity, concentrating on supplying RUTF to UNICEF and other NGOs. In North America, regional manufacturers are engaged in the production of RUTF and RUSF, supplying them to infants in a number of African nations such as Kenya, Sudan, Ethiopia, Burkina Faso, and Nigeria. In Asia Pacific, the implementation of CMAM in various countries such as India, Pakistan, Bangladesh, Bhutan, and Afghanistan has helped the market grow. Some of the key companies currently operating in the global ready-to-use therapeutic food and supplementary food market are: Mana Nutritive Aid Products, Nutriset SAS, Valid Nutrition, InnoFaso, GC Rieber Compact AS, Tabatchnik Fine Foods, Edesia Nutrition, Diva Nutritional Products, Hilina, Insta Products, NutriVita Foods, Kaira District Cooperative, 13.3.15. Meds \& Food For Kids, Nuflower Foods and Nutrition Pvt., Samil Industrial Co., and Power Foods Tanzania (UNICEF Supply Division, 2021).

Nutriset itself has introduced several new products including Plumpy'Sup ${ }^{\mathrm{TM}}$ (supplementary food for stunted children), Plumpy'Mum ${ }^{\mathrm{TM}}$ (supplementary food for pregnant and lactating women), Plumpy'Doz ${ }^{\mathrm{TM}}$ (micronutrient enriched supplementary food), Enuv'Mum ${ }^{\mathrm{TM}}$ and Enuv'Nutributter ${ }^{\mathrm{TM}}$ (micronutrient enriched foods for children and mothers with calorie adequate but low micronutrient value diets), which are being produced in large quantities, in addition to other products (Nutriset, 2018).

Though Edesia Nutrition ${ }^{4}$ claimed to be a non-profit endeavour, its former web site spoke only of business opportunities, annual sales plans, improving brand image and market research; it said nothing about public nutrition or improving the nutrition situation. However, business opportunities with Edesia Nutrition are not currently displayed on their website. Other RUTF manufacturers also view manufacturing and supplying RUTF and RUSF as a business opportunity. Valid Nutrition, as mentioned earlier in this paper, not just manufactures RUTF for profit, but also uses it for its programs and provides technical inputs and knowledge about treatment of SAM using RUTF.

\footnotetext{
${ }^{4}$ Inspired by a 60-minute episode on Plumpy'nut, Navyn Salem, financed by her venture capitalist husband, started Edesia Nutrition by becoming a Nutriset licensee in 2009; the factory doubled its capacity for production in 2016.
} 
Companies take innovative measures to increase the market for RUTF. Calorie Cloud, a partner of MANA Nutrition as well as UNICEF, uses the public private partnership (PPP) route and publicizes "recycling" of the reader's calories by counting activity and weight loss, and donating equivalent RUTF packets produced by MANA. According to Mark Moore, CEO of MANA Nutrition, "Through the Calorie Cloud, consumers in the U.S. or other developed countries can exercise or diet, and then "contribute" their calories to severely malnourished children around the world. There will be many ways that calories can be monetized; individual users can pay to the cloud via PayPal or other electronic transfer at .30 cents per 500 calories. As the cloud grows, they plan to have donor companies who will pay for calories both because it makes sense for them as a business case (i.e. corporate wellness or insurance companies or food companies) or because they believe in the mission (Sasha Banks-Louie, 2019). In addition, the company is also partnering with Operation Smile, who use MANA packets to treat malnourished babies born with cleft lips or palates.

Other companies are resorting to other, sometimes questionable, marketing practices, especially for Plumpy'nut. A company called This Bar Saves Lives gives a packet of Plumpy'nut for each ultra-processed snack purchased. Also using the PPP route, US company Toddler Food Partners provides knowledge and equipment to produce RUTF. In India, it has already partnered with Hexagon Nutrition Private Limited, General Mills India Office, State Nutrition Mission, and Tata chemicals, among other companies.

The marketing materials of private companies, including Edesia Nutrition, sometimes violate the human right to dignity of the SAM child. They use photos of undernourished coloured, half naked children from poor countries, clutching packages of RUTF and testimonials of mothers lauding the product (Mana, undated; Edesia, undated; Nutrivita Foods (undated); Valid Nutrition (undated). Often there are before and after photosets. All these visuals are employed to emotionally reach out to sponsors and donors.

\section{CONCLUSIONS}

It is a well-known fact that more children die from mild or moderate undernutrition than due to severe wasting (Pettelier et al., 1995; Sardeshpande et al., 2009). The focus on marketing and sales of RUTF originally focused on the much smaller SAM market but now is extended to both treatment and prevention of malnutrition, a huge commercial enterprise, amounting to exploiting undernutrition for profits and poseing ethical questions.

Undernutrition (and also micronutrient deficiency) has multiple causes, one of which is the lack of adequate amounts of diverse foods. Besides conflict and war, and natural emergencies, this lack is primarily due to inequality among people between and within nations, gender inequity, uncontrolled volatile markets, inadequate knowledge of IYCF and poor basic health care. A study in Southern Ethiopia noted, "Even though health workers provide RUTF as a treatment for SAM children, their caregivers use it also for meeting broader food and economic needs of the household, endangering the effectiveness of CMAM programme. In chronically food insecure contexts, interventions that also address economic and food needs of entire household are essential to ensure successful treatment of SAM children. This may need a shift to view SAM as a symptom of broader problems affecting a family rather than a disease in an individual child" 
(Tadesse et al., 2015). These are issues that need to be looked at to provide a long-term, sustainable solution to undernutrition.

A 2004 guideline developed by UNCHR, UNICEF, WFP and WHO states "At the onset of an emergency, ensuring an adequate basic ration for the needy population is crucial. The quick provision of an adequate ration not only saves lives, but also reduces the likelihood of later having to introduce more costly and cumbersome interventions such as selective feeding programmes" (WHO, 2004). The guidelines stressed community participation: "To meet the food and nutritional needs of the population more effectively, the planning of the food ration should be carried out with the participation of the affected community. Women in particular should be consulted during the process of determining the appropriate food and nutritional needs of the affected population" (WHO, 2004).

These guidelines are still relevant in managing malnutrition, in both emergency and nonemergency situations, as can be seen by the experience with community kitchens in Marawi, Philippines (UNICEF Philippines, 2017) and Karadapanga hamlet in India (Ghosh, 2020). Kitchen gardens are particularly useful, as they reduce household expenditure while enhancing affordable access to food (Rybak et al., 2018; Savita Arya et al., 2018; Mohsin et al., 2017).

Community programs such as Action Against Malnutrition in four states of India showed that providing effective childcare facilities through well-managed affordable creches for children under three years of age, as well as increasing the calorie content of home cooked food by adding an extra teaspoon of oil, reduced the incidence of SAM and MAM (Prasad \& Sinha, 2015). This also raised the family income by allowing women to work without worrying about their young children, and allowed elder siblings to attend school rather than providing childcare services in the family. Additionally, as the caregivers learnt how to care for and feed the child, relapse rates were lower than in those treated with RUTF. The program was developed with the women of the community, who also supervised its implementation (Prasad \& Sinha, 2015). The government of Odisha in India scaled up this model of CMAM in selected districts. Data analysis between October 2017 and October 2020 reveals that among 156 severely wasted children in the program, $87.2 \%$ showed improvements in grades: approximately $39.1 \%$ shifted from severely wasted to normal category, while $48.1 \%$ shifted from severely wasted to moderately wasted category (PHRS \& APPI, 2020).

Sustainable interventions designed with community participation to reduce SAM and other forms of malnutrition empower communities and families to address malnutrition holistically and build their self-reliance to manage and prevent malnutrition with available resources.

\section{Acknowledgements}

I would like to thank Dr. Ted Greiner encouraging me to adapt and update an old unpublished paper that I shared with him.

\section{Conflict of interest}

None 


\section{REFERENCES}

Arie S. (2010). Hungry for Profit. BMJ 341. https://doi.org/10.1136/bmj.c5221

Arya S., Prakash S, Joshi S, Tripathi KM, Singh V. (2018). Household Food Security through Kitchen Gardening in Rural Areas of Western Uttar Pradesh, India. Int. J. Curr. Microbiol. App. Sci 7(2): 468-474. https://doi.org/10.20546/ijcmas.2018.702.058

Bhandari N, Mohan SB, Bose A, lyengar SD, Taneja S, Mazumder S, Pricilla RA, lyengar K, Sachdev HS, Mohan VR, Suhalka V. (2016). Efficacy of three feeding regimens for home-based management of children with uncomplicated severe acute malnutrition: a randomised trial in India. BMJ Global Health 1(4):e000144.

Bhutta ZA, Das JK, Rizvi A, Gaffey MF, Walker N, Horton S, Webb P, Lartey A, Black RE; Lancet Nutrition Interventions Review Group, the Maternal and Child Nutrition Study Group. (2013). Evidence-based interventions for improvement of maternal and child nutrition: what can be done and at what cost? Lancet 382(9890):452-477. doi: 10.1016/S0140-6736(13)60996-4 Erratum in: Lancet. 2013;382(9890):396.

Department for International Development, UK Aid. (2018). Assessment of DIFD's Ready-to-use Therapeutic Food (RUTF) Program (2014-2017) to the Global RUTF Market - Final Report.

Edesia. (2016). Edesia Nutrition Our Current Openings: Business Development Manager. http://www.edesianutrition.org/wp-content/uploads/2016/05/busdevmanager052316.pdf Cited in Bazzano, A. N., Potts, K. S., Bazzano, L. A., \& Mason, J. B. (2017). The Life Course Implications of Ready to Use Therapeutic Food for Children in Low-Income Countries. International journal of environmental research and public health, 14(4):403. https://doi.org/10.3390/ijerph14040403

Edesia. (undated). https://www.edesianutrition.org/about-us/

Ghosh R. (2020). Community kitchens help tribal children overcome malnutrition. https://www.villagesquare.in/2020/01/31/community-kitchens-help-tribal-children-overcomemalnutrition/

Gope RK, et al. (2019) Effects of participatory learning and action with women's groups, counselling through home visits and crèches on undernutrition among children under three years in eastern India: a quasi-experimental study. BMC Global Health 19:962. https://doi.org/10.1186/s12889-019-7274-3

Greiner T. (2014). The advantages, disadvantages and risks of ready-to-use foods. Breastfeeding Briefs No. 56/7:1-17.

Huybregts L, Houngbé F, Salpéteur C, et al. (2012). The effect of adding ready-to-use supplementary food to a general food distribution on child nutritional status and morbidity: a cluster-randomized controlled trial. PLoS Med 9(9):e1001313. https://doi.org/10.1371/journal.pmed.1001313

IBFAN policy brief, October 2017.

International Finance Corporation. (2017). Investing in Postwar Yemen Means Investing in Nutrition Now. 
https://www.ifc.org/wps/wcm/connect/news ext content/ifc external corporate site/news+and+eve nts/news/impact-stories/investing-in-postwar-yemen-means-investing-in-nutrition-now

Mana Nutrition. (undated).

https://m.facebook.com/ManaNutrition/photos/a.149906447871/10157672447377872/?type=3\&sourc $\mathrm{e}=48 \&$ tn $=E H-R$

McGrath M, Angood C. (2020). Editorial. Field Exchange, 63:3.

https://www.ennonline.net/fex/63/editorial

Muhammad Mohsin, Muhammad Mushahid Anwar, Farrukh Jamal, Fahad Ajmal \& Juergen Breuste. (2017). Assessing the role and effectiveness of kitchen gardening toward food security in Punjab, Pakistan: a case of district Bahawalpur. International Journal of Urban Sustainable Development 9(1):6478. DOI: $10.1080 / 19463138.2017 .1286349$

NAPi. (2017). New study on severe malnutrition breaks the myth that management with RUTF is a miracle. http://www.napiindia.in

Nutriset. (2018). https://www.nutriset.fr/en/products

Nutrivita Foods. (undated). https://nutrivita.in/

Pelletier, David L, Frongillo, Edward A, Schroeder, D. G \& Habicht, J. P. (1995). The Effects of malnutrition on child mortality in developing countries. Bulletin of the World Health Organization 73(4):443-448.

https://apps.who.int/iris/handle/10665/47438

Prahalad CK, Hart, SL. (2002). Fortune at the Bottom of the Pyramid. Strategy + Business. Wharton School Pub, Issue 26. https://www.strategy-business.com/article/11518

Prasad V and Sinha D. (2015). Potentials, experiences and outcomes of a comprehensive communitybased programme to address malnutrition in tribal India. International Journal of Child Health and Nutrition 4:151-162.

Prasad V. (2017). Foregrounding 'Community' in Community Management of Severe Acute Malnutrition: An Indian Perspective. World Nutrition 8(1):79-86. https://doi.org/10.26596/wn.20178179-86

Prasad V. (2017). Reading Between the Lines of the RUTF trial, India. Letter to the editor, response to Bhandari N. et al. BMJ Glob. Health.

Prasad V. (2026). Representing Community-Based Action on Nutrition. Paper presented at the World Public Health Nutrition Association Conference, Cape Town.

Prorodeo. (2021). Strategic Trends in Global Ready-to-use Therapeutic Food (RUTF) Market 2021 Share, Size, Growth and Future Demand by Major Players, Trending Technologies, Potential Revenue Analysis 2026. https://www.thecowboychannel.com/story/43410693/strategic-trends-in-global-ready-to-usetherapeutic-food-rutf-market-2021-share-size-growth-and-future-demand-by-major-players-trendingtechnologies

Public Health Resource Network \& Azim Premji Philanthropic Initiatives. (2020). Mainstreaming Creches to Reduce malnutrition in Odisha: Data analysis October 2017 to October 2020. Available with Public Health Resource Society. 
Rybak, C., Mbwana, H.A., Bonatti, M. et al. (2018). Status and scope of kitchen gardening of green leafy vegetables in rural Tanzania: implications for nutrition interventions. Food Sec. 10:1437-1447. https://doi.org/10.1007/s12571-018-0869-1

Sardeshpande N, Shukla A, and Scott K (eds). (2009). Nutritional Crisis in Maharashtra, Support to Advocacy and Training to Health Initiatives (SATHI). http://napiindia.in/docs/EPW-article-Let-them-eatpaste.pdf

Sasha Banks-Louie. (2019). With milk and peanut butter, nonprofit lowers cost to fight childhood malnutrition. Forbes Magazine. https://www.forbes.com/sites/oracle/2019/05/02/with-milk-andpeanut-butter-nonprofit-lowers-cost-to-fight-childhood-malnutrition/?sh=487f7b162150

Shintre, K. (2017). Ready to Use Therapeutic Food from Locally Available Food Ingredients for Children with Severe Acute Malnutrition in India. http://www.peah.it/2017/10/ready-to-use-therapeutic-foodfrom-locally-available-food-ingredients-for-children-with-sam-in-india/

Steenkamp L, Lategan R \& Raubenheimer J. (2015). The impact of ready-to-use supplementary food (RUSF) in targeted supplementation of children with moderate acute malnutrition (MAM) in South Africa, South African Family Practice 57(5):322-325. DOI: 10.1080/20786190.2015.1078153

SUN Movement. (2015). Scaling Up Nutrition. http://scalingupnutrition.org/

Tadesse E, Berhane Y, Hjern A, Olsson P, Ekström EC. (2015). Perceptions of usage and unintended consequences of provision of ready-to-use therapeutic food for management of severe acute child malnutrition. A qualitative study in Southern Ethiopia. Health Policy Plan. 30(10):1334-41. doi: 10.1093/heapol/czv003.

Thekleberhon, M. (2012). Pepsi and USAID Partnering to Combat Malnourishment in Ethiopia. https://www.2merkato.com/news/manufacturing/1247-pepsi-and-usaid-partnering-to-combatmalnourishment-in-ethiopia

Transparency Market Research. (2017). Ready-to-use Therapeutic Food and Supplementary Food (RUTF \& RUSF) Market - Global Industry Analysis 2017 - 2025: TMR. https://www.prnewswire.com/newsreleases/ready-to-use-therapeutic-food-and-supplementary-food-rutf--rusf-market---global-industryanalysis-2017---2025-tmr-640309973.html

UNICEF Philippines. (2017). Community kitchens in evacuation centers help prevent malnutrition among young children displaced from Marawi. https://medium.com/@unicefphils/community-kitchens-inevacuation-centers-help-prevent-malnutrition-among-young-children-displaced-a2d1096df712

UNICEF Supply Division. (2018). Ready-to-Use-Therapeutic-Food: Current Outlook.

UNICEF Supply Division. (2021). Ready-to-Use Therapeutic Food: Market Outlook. https://www.unicef.org/supply/media/7256/file/RUTF-Supply-Update-March-2021.pdf

UNICEF. (2013). Ready-to-use therapeutic food for children with severe acute malnutrition. Current issues 1. New York 
UNICEF. (2019). Updates on Nutrition Product Regulatory Status and the Essential Medicines List (EML). https://www.unicef.org/supply/media/3401/file/ NSF-2019-1630-Regulatory-updates-NutritionCommodities.pdf

USAID. (2017). Nutrition in Emergencies: Technical Guidance Brief. https://www.usaid.gov/what-wedo/global-health/nutrition/technical-areas/nutrition-emergencies-technical-guidance-brief\# ftn20

Valid Nutrition (undated). https://www.validnutrition.org/products-overview/

Valid Nutrition. (2016). Annual Review of 2015. http://www.validnutrition.org/wpcontent/uploads/2016/03/Annual-Report-2015-Final-.pdf

VALID Nutrition. (2020). Annual Review of 2020. https://www.validnutrition.org/wpcontent/uploads/2021/01/Annual-Report-2020.pdf

WFP/UNICEF/USAID. (Undated). Harmonization of lipid-based products. http://nutritionuat.kelltontech.net/sites/default/files/2020-01/Harmonization-of-lipid-based-productsUNICEF-WFP-USAID.pdf

WHO. (2000). The Management of Nutrition in Major Emergencies. https://www.globalhealthlearning.org/sites/default/files/pagefiles/MAM\%2C\%20SAM\%2C\%20and\%20GAM.pdf

WHO. (2012). Technical note: Supplementary foods for the management of moderate acute malnutrition in infants and children 6-59 months of age. Geneva: World Health Organization. https://apps.who.int/iris/bitstream/handle/10665/75836/9789241504423 eng.pdf?sequence=1\&isAllo wed $=y$

WHO. (2014). WHA Global Nutrition Targets 2025: Wasting Policy Brief. https://www.who.int/nutrition/topics/globaltargets wasting policybrief.pdf

WHO. (2020). Factsheet. Malnutrition. https://www.who.int/news-room/fact-sheets/detail/malnutrition WHO. (2020). https://www.who.int/nutgrowthdb/estimates/en/ WHO/UNICEF/WFP (2014). Global nutrition targets 2025: wasting policy brief (WHO/NMH/NHD/14.8). Geneva: World Health Organization. http://apps.who.int/iris/bitstream/10665/149023/1/WHO NMH NHD 14.8 eng.pdf?ua=1

World Health Organization, the World Food Programme, the United Nations System Standing Committee on Nutrition and the United Nations Children's Fund. (2007). Community-based management of severe acute malnutrition. A Joint Statement. https://apps.who.int/iris/bitstream/handle/10665/44295/9789280641479 eng.pdf 